\title{
VIEJOS Y NUEVOS DATOS SOBRE LA CONTROVERSIA POÉTICO-TEOLÓGICA ENTRE JUAN DE ALCALÁ Y JORGE DE MONTEMAYOR*
}

Hoy podemos decir que Jorge de Montemayor fue el poeta del siglo XVI cuya obra lírica alcanzó mayor difusión impresa en vida de su autor $^{1}$. El dato ha ido emergiendo gracias a sucesivas pesquisas bibliográficas que nos permiten tener un conocimiento cada vez más completo del proceso editorial que vivieron sus versos ${ }^{2}$. Dejando a un lado los pliegos sueltos aparecidos entre 1545 y $1552^{3}$, el empeño creativo del portugués se cifró en la composición de un cancionero con dos secciones, una de poesía profana y otra de poesía devota, cada una de las cuales tenía una parte octosilábica y otra italianizante -Montemayor fue el primero en aplicar la nueva métrica a la materia

* Este trabajo forma parte del proyecto I+D, "El canon de la lírica áurea: constitución, transmisión e historiografía" (BFF 2003-0765).

${ }^{1}$ El linarense Pedro de Padilla, que podría disputarle ese honor, es ciertamente un autor más prolífico, con seis títulos impresos; pero su obra más difundida en la época, el Tesoro de varias poesías, sólo se imprimió tres veces (Madrid, 1580, 1587 y 1589). Si no en términos absolutos, Montemayor le saca ventaja en proporción.

${ }^{2}$ Hasta la fecha, la relación bibliográfica más completa es la de SANTIAGO GonZáleZ y Fernández-Corugedo, "Ediciones de la poesía profana de Jorge de Montemayor", $A O, 36$ (1986), 413-420. La edición más cuidada ahora accesible es la Poesía completa, ed. J. B. de Avalle-Arce, con la colab. de E. Blanco, Biblioteca Castro, Madrid, 1996. Próximamente aparecerá en la editorial Castalia una antología preparada por Elizabeth Rhodes y quien suscribe.

${ }^{3}$ Conocemos tres de ellos: Glosa de diez coplas de don Jorge Manrrique... sobre la muerte de la muy alta princesa doña María hija del Rey don Juan tercero de Portugal, ¿Lisboa, 1545? (ed. facs. en M. Cruz García de Enterría, Pliegos poéticos de la Biblioteca Nacional de Lisboa, Joyas Bibliográficas, Madrid, 1975, núm. 3). Exposición moral sobre el psalmo lxxxvi del real profeta David, Juan de Brócar, Alcalá, 1548 (ed. facs. en Pliegos poéticos góticos de la Biblioteca Nacional de Madrid, Joyas Bibliográficas, Madrid, 19571961, t. 6, núm. 190). Cancionero de las obras de devoción de Jorge de Montemayor, ¿Junta, Burgos?, 1552 (ed. facs. reducida en JeAn Dupont, "Un pliego suelto de 1552 intitulé: Cancionero de las obras de devoción de Jorge de Montemayor", BHi, 75, 1973, 40-72). Son, respectivamente, los núms. 383, 381 y 380.5 de Antonio Rodríguez-Moñino, Nuevo diccionario bibliográfico de pliegos sueltos poéticos. (Siglo XVI), ed. corregida y actualizada A. L.-F. Askins y V. Infantes, Castalia-Editora Regional de Extremadura, Madrid, 1997. 
religiosa. La plasmación editorial de ese empeño es el volumen titulado Las obras, que va dedicado a los príncipes de Portugal, Don Juan y Doña Juana de Austria. Hasta hace unos años se identificaba ese cancionero de manera exclusiva con la edición de Amberes, Iuan Steelsio (pero Iuan Lacio en el colofón), 1554. Hoy sabemos que hubo, al menos, otras dos ediciones de esa colección poética: una en Medina del Campo, Guillermo de Millis, 1552 o 1553, que debe ser considerada la princeps ${ }^{4}$, y otra, en Estella, Adrián de Amberes, $1556^{5}$. Además, hay unas Obras de amores que aparecieron en Zaragoza, Esteban de Nágera, 1554, conteniendo la parte profana y, para completar pliego, el primer poema de la sección religiosa ${ }^{6}$. Con posterioridad, Montemayor revisó su obra, suprimiendo y añadiendo poemas, y el resultado se publicó en dos volúmenes independientes, el Segundo cancionero, dedicado al duque de Sessa, y el Segundo cancionero espiritual, ambos impresos en Amberes, Iuan Lacio, 1558. La trayectoria editorial de esos dos libros fue muy distinta, ya que en 1559 los versos devotos de Montemayor fueron objeto de una condena inquisitorial que, lógicamente, cortó de raíz su difusión 7 . En cambio, la produc-

\footnotetext{
${ }^{4}$ Se conservan dos ejemplares de esa edición, sine notis y mútilos de la sección religiosa: uno en la Hispanic Society de Nueva York (ex Marqués de Jerez de los Caballeros, identificado entre interrogaciones como Andrés de Burgos, Évora, ca. 1553 en Clara L. Penney, Printed books 1468-1700 in the Hispanic Society of America. A listing, The Hispanic Society of America, New York, 1965, p. 368), y otro en la Bayerische Staatsbibliothek (sign.: 4 P.O.hisp. 54; su existencia la dio a conocer J. Dupont, art. cit., p. 68). La identificación de esos ejemplares como impresos en Medina del Campo por Guillermo de Millis en 1552 o 1553 se debe a Jaime Moll, quien tuvo la generosidad de comunicárnosla en carta personal, cf. nuestro "Sobre imprenta y poesía a mediados del XVI (con nuevos datos sobre la princeps de Las obras de Jorge de Montemayor)", en prensa en Bulletin Hispanique.

${ }^{5}$ Se conoce hasta ahora un solo ejemplar: el R 39720 de la BNM; véase MERCEDes Dexeus, "La primera edición española del Cancionero de Montemayor con las obras devotas de Juan Fernández de Heredia”, Trabajos de la Asociación Española de Bibliografía, AEB, Madrid, 1998, t. 2, pp. 277-281.

${ }^{6}$ El único ejemplar que se conoce hasta ahora de esta edición también se custodia en la Hispanic Society de New York. Procede asimismo de los libros del MARQuÉs DE Jerez de los Caballeros (que lo describió en "Unas papeletas bibliográficas", Homenaje a Menéndez Pelayo en el año vigésimo de su profesorado. Estudios de erudición española, Victoriano Suárez, Madrid, 1899, t. 2, pp. 639-644), y está repertoriado entre interrogaciones como impreso en Zaragoza por Esteban de Nájera (C. L. Penney, op. cit., p. 368), identificación que Jaime Moll ha tenido la amabilidad de confirmarnos como correcta.

${ }^{7}$ La prohibición original reza así: "Obras de George de Monte Mayor, en lo que toca a devocion y cosas Christianas” (J. M. DE BUJANDA, Index de l'Inquisition espagnole 1551, 1554, 1559, Droz-Centre d'Études de la Renaissance-Éditions de l'Université de Sherbroke, Genève, 1984, pp. 513-514); y fue confirmada en 1583: "Iorge de Montemayor, sus obras tocantes a devocion y religion" (J. M. DE BuJANDA, Index de l'Inquisition espagnole 1583, 1584, Droz- Centre d'Études de la Renaissance-Éditions de l'Université de Sherbroke, Genève, 1993, p. 604). La importancia de la poesía devota de Montemayor, en particular de las composiciones de inspiración bíblica, fue
} 
ción profana pudo continuar su andadura, con el título de Cancionero. Pero la primera edición conocida de esta colección, la de Zaragoza, viuda de Bartolomé de Nágera, 1562, ya es póstuma, dado que el poeta había muerto el año anterior en el Piamonte, en circunstancias poco claras hasta hoy ${ }^{8}$.

Una consecuencia no deseada, aunque conexa, con semejante notoriedad editorial fue la de hacer de Montemayor y de sus versos el blanco de algunos ataques por parte de otros colegas de pluma -al margen de la prohibición inquisitorial, que representaba la forma más extrema de censura crítica en la época. Tenemos noticia en concreto de dos de esas arremetidas. La menos difundida es obra del poeta sevillano Juan Iranzo y consiste en una epístola en tercetos que toma como objeto de sátira diversas expresiones y conceptos de Las $o b r a s^{9}$. La más conocida es la que le dirigió, en coplas reales, un tal Juan de Alcalá, por lo que sabemos, calcetero de profesión y aficionado a concursar en justas poéticas - de ello nos ocuparemos más abajo. Éste denunció y corrigió un error teológico concerniente nada menos que a la Trinidad en un pasaje de La Passión de Christo, largo poema de la sección devota de Las obras que narra la pasión y muerte de Jesús en 236 coplas reales ${ }^{10}$. Montemayor respondió de manera

destacada por Marcel Bataillon, "Une source de Gil Vicente et de Montemôr: la méditation de Savonarole sur le Miserere" (1936), Études sur le Portugal au temps de l'humanisme, Impresa da Universidade, Coimbra, 1952, pp. 197-217. Véase, asimismo, Michel Darbord, La poésie religieuse espagnole des Rois Catholiques à Philippe II, Centre de Recherches de l'Institut d'Études Hispaniques, Paris, 1965, pp. 333-425; BrYANT L. CREeL, The religious poetry of Jorge de Montemayor, Tamesis, London, 1981; y ELIZABETH RHODEs, The unrecognized precursors of Montemayor's "Diana", University of Missouri Press, Columbia-London, 1992, pp. 20-107.

${ }^{8}$ Se trata de un volumen que recoge el contenido del Segundo cancionero de 1558, salvo un largo poema en octavas reales titulado Historia de Alcida y Silvano (ed. E. Rhodes, recogido en Dicenda, 2, 1983, 121-134 y 203-236); también mantiene la dedicatoria al duque de Sessa que ya figuraba en aquél. En los preliminares, sin embargo, se incorporan materiales nuevos, singularmente una elegía de Francisco Marcos Dorantes a la muerte de Montemayor. Se conocen un total de seis impresiones de esta colección entre 1562 y 1588.

${ }^{9} \mathrm{El}$ poema, del que se conocen dos copias manuscritas, fue editado por LucAs DE TORRE, "Algunas notas para la biografía de Gutierre de Cetina", BRAE, 11 (1924), pp. 399-401. De él nos ocupamos en "Una epístola olvidada de Juan Iranzo, poeta sevillano, contra Jorge de Montemayor", en prensa en el Homenaje a Cristóbal Cuevas que publicará la Universidad de Málaga.

${ }^{10}$ El poema puede leerse en Poesía completa, ed. cit., pp. 175-252. Lleva una dedicatoria a don Manrique de Lara, duque de Nájera, conde de Treviño y de Valencia de Don Juan. La dedicatoria desaparece, sin embargo, en el Segundo cancionero espiritual (ibid., pp. 819-896), al igual que una copla "Al lector" que precedía la composición. No está de más recordar en este contexto que Las obras de Montemayor contaban para su impresión con una aprobación eclesiástica extendida por fray Pedro de Alconada, dominico en el convento de San Andrés el Real de Medina del Campo; el documento acreditativo, que no figura en Las obras, fue editado por NARCISo Alonso Cortés, "Sobre Montemayor y La Diana”, BRAE, 17 (1930), pp. 354-356. 
vehemente y su contrincante replicó otra vez, generándose así una controversia en la que la materia poético-teológica se revolvió con la más prosaica de los insultos y descalificaciones personales.

El pasaje de la Pasión que llamó la atención de Juan de Alcalá está en el arranque mismo del poema:

Siendo ya el tiempo llegado

en que Cristo determina

de ponerse en tal estado

que caya sangre divina

sobre el humano pecado,

se puso el Señor en pie,

con sus discípulos junto,

a la mesa donde fue

hecho y ordenado el punto

más delicado de fe.

Y estando allí el Uno y Trino

con su compaña real,

luego en ese instante vino

el cordero material

ante el Cordero divino.

Uno, sin vida, a la llana;

y el otro, sobre quien pesa

la reparación humana.

Uno está de noche en mesa,

y otro en cruz por la mañana ${ }^{11}$.

Concretamente, Alcalá reparó en que Montemayor confundía en el v. 11 a Cristo, una persona de la Trinidad, con la Trinidad misma, de manera que, entre frases más o menos elogiosas, se permitió sermonear al lusitano sobre los términos correctos en que debía entender ese dogma, para terminar amonestándole: "vélate bien en trovar, / porque con su leña el monte / se suele a veces quemar" (vv. 52-55). En su respuesta, Montemayor trató de justificar el pasaje con sutilezas escolásticas ${ }^{12}$ y descargó su ira acusando a su oponente de cris-

${ }^{11}$ Editamos el texto teniendo a la vista las ediciones antiguas, pero modernizando grafías, acentuación y puntuación. Hemos enmendado la hipermetría del v. 10 en Las obras: ("más delicado de la fe") con la lectura del Segundo cancionero espiritual; cf. Poesía completa, pp. 177 y 819.

12 Razona el lusitano que se puede decir de Cristo, en cuanto Dios, que es uno y trino concomitantiae ratione. Este tecnicismo lo empleó, por ejemplo, SANTO TOMÁS DE AQuino, Contra errores Graecorum, pars. 1, cap. 13: “...sed intelligitur in nomine Christi spiritus sanctus ratione concomitantiae, quia ubicumque est Christus, est spiritus Christi, sicut ubicumque est pater, est filius". Por otra parte, el Aquinate explicaba como ex reali concomitantia (STH III, q. 76, a. 1 ad 1) la presencia plena de Cristo, hombre y Dios, en cada una de las especies sacramentales, doctrina que quedó consagrada en el concilio de Trento; Juan de Alcalá lo sabía, como queda claro en su 
tiano nuevo, lo que no hizo sino enconar la cuestión. Alcalá volvió a la carga remachando su denuncia con nuevos argumentos y tachando a Montemayor de converso y aun de judaizante. En el Segundo cancionero espiritual, donde el verso de marras ya aparece retocado: "Y estando Jesú benigno / con su compaña real..."13, encontramos la prueba de que el lusitano hubo de rendirse a la evidencia.

La disputa alcanzó amplia difusión manuscrita en la época -de eso hablaremos más abajo-y no ha pasado inadvertida para los estudiosos contemporáneos. La primera fuente para su conocimiento fue la copia contenida en la Miscelánea de Luis Zapata (ms. 2790 de la Biblioteca Nacional), tras su impresión en $1859^{14}$. Con posterioridad se han editado otras tres copias de la controversia: la del ms. II-1580 de la Biblioteca Real, la del ms. 17681 de la Nacional y, recientemente, la del ms. F. G. Cod. 3072 de la Nacional de Lisboa ${ }^{15}$. De esta manera, no han faltado alusiones a la polémica en los estudios sobre Montemayor, especialmente a la hora de discutir sus mal conocidos orígenes familiares y su presunta ascendencia judaica ${ }^{16}$.

primera réplica: "Ni pertenece a tu cuento / concomitantiae ratione, / porque este acompañamiento / en el Santo Sacramento / se dirige y se dispone" (vv. 61-65). En realidad, Montemayor hubiera podido buscar mejor amparo en otro principio doctrinal, el de la circumincesión o "perfecta inmanencia de las divinas personas en relación de las unas con las otras" (José López Toro, "El poeta sevillano Juan de Alcalá", Archivo Hispalense, Sevilla, 1951, núm. 14, p. 10). En Las obras del lusitano trata específicamente de la Trinidad la última sección de la glosa del salmo Fundamenta eius in montibus sanctis (Poesía completa, pp. 160-162); lo mismo ocurre en el arranque de otra obra de Montemayor: Diálogo espiritual, ed. M. D. Esteva de Llobet, Reichenberger, Kassel, 1998, pp. 101-105.

${ }^{13}$ Cf. Poesía completa, p. 819.

14 Memorial Histórico Español, t. 11, Imprenta Nacional, Madrid, 1859. La polémica ocupa las pp. 279-291 y va precedida del rótulo: "De una agradable competencia de dos trobadores de España”. Es transcripción poco fiel de los ff. 249-252v del citado ms. 2790, ya que, entre otras cosas, faltan dos quintillas y aparece alterado el orden de las estrofas. Sobre el autor y su obra, véase Francisco Márquez Villanueva, "Don Luis Zapata, el sentido de una fuente cervantina", Fuentes literarias cervantinas, Gredos, Madrid, 1973, pp. 109-182.

${ }^{15}$ Son, respectivamente, FRAY Luis G. Alonso Getino, Anales salmantinos, t. 2: Nueva contribución al estudio de la lírica salmantina del siglo XVI, Establecimiento Tipográfico de la Calatrava, Salamanca, 1929, pp. 332-343; J. López Toro, art. cit., pp. 20-28, texto reproducido en B. L. Creel, op. cit., pp. 257-263; y, finalmente, Cancionero sevillano de Lisboa, eds. J. J. Labrador Herraiz, R. A. DiFranco y A. López Budia, pról. B. López Bueno, Universidad, Sevilla, 2003, pp. 71-80.

16 Véanse, entre otros, Jorge DE Montemayor, La Diana, ed. F. López Estrada, Espasa-Calpe, Madrid, 1954, pp. xiv-xv; M. DARbord, op. cit., pp. 335-340; F. MárQueZ Villanueva, "Los joyeles de Felismena", RLC, 52 (1978), pp. 268-269, sobre la condición de platero u orfebre que Alcalá atribuía al padre de Montemayor; E. RHODES, op. cit., pp. 22-23. En relación con esto, nótese que Julio CARo BAROJa menciona el cruce de acusaciones entre los dos ingenios como un ejemplo de conversos burlándose en otro de su propia condición (Los judios en la España contemporánea, Arión, Madrid, 1962, t. 1, pp. 288-289). 
Juan de Alcalá y su actividad poÉtica

¿Quién era el tal Juan de Alcalá? Es difícil saberlo con exactitud, dado que las únicas informaciones disponibles son las que nos transmiten los diferentes testimonios de la polémica, y éstos no coinciden en todo sobre ese particular. Algunos manuscritos hacen de él un calcetero, sastre o ropero sevillano en el rótulo que precede a los textos de la disputa, y como sevillano lo consideró José López Toro en el artículo ya citado. Que nuestro hombre fuese del gremio de la aguja es noticia transmitida, no sabemos con qué fundamento, por Montemayor, que en un pasaje de su respuesta le echa en cara "...saltar de puntos de aguja / en puntos de teología" (vv. 9-10)17.

En cuanto a la presunta sevillanía de Alcalá, puede aducirse como prueba confirmatoria la presencia de un poeta homónimo entre los participantes en una justa poética sevillana de 1541 en honor de san Isidoro ${ }^{18}$, así como la atribución de sendos poemas en el ms. 2495 de la Hispanic Society y en el conocido como Fuenmayor (Biblioteca General del CSIC, fondo Rodríguez Marín 3879), dos códices que copian abundantes composiciones procedentes de justas sevillanas ${ }^{19}$. La aparente contundencia de estos datos se ve, sin embargo, desmentida por la información que transmite otro de los códices que copia la polémica, concretamente el ms. II-1580 de la Biblioteca Real, conocido como Cartapacio de Ramiros Cid y Piscina. Este testimonio - editado en su día por Alonso Getino, pero desconocido para López Toro- tiene la particularidad de ser el único (hasta ahora) en presentar los textos de la controversia precedidos por una nota que da cuenta de las circunstancias que la originaron. La nota dice así:

En la villa de Alcalá de Henares se tiene por costumbre de dar el día de la Asumpçión de Nra. Señora vn premio al poeta que mejor obra aquel día sacare en loor de la Reina del çielo. Avía en la dha. villa vn calçetero llamado Juan de Alcalá, el qual ganó estos premios muchos años en conpetençia de muy buenos ingenios que hazían obras marauillosas en loor de Nra. Señora, porque sin duda era estremado poeta y a todos

17 En la réplica subsiguiente, Alcalá parece dar por buena esa caracterización: "Si yo salté de coser / en puntos de teologar, / es cristiano mi saber" (vv. 81-83). J. López Toro, sin embargo, se pregunta: "Era, en efecto, Juan de Alcalá un sastre sevillano...? ¿ $\mathrm{O}$ más bien era un pseudónimo bajo el cual se ocultaba alguno de los muchos teólogos que florecían en aquella época?” (art. cit., p. 17).

${ }^{18}$ Se trata de la composición que empieza "Ya después quel plantador"; véase Santiago Montoto, Justas poéticas sevillanas, Castalia, Valencia, 1955, p. 347.

${ }^{19} \mathrm{El}$ primer poema lleva el rótulo Justa de la Encarnación por Alcalá (in: "María diuina esposa") y ocupa los ff. 18v-19v. El segundo poema va rotulado Justa literaria en alabança de Sant Anna por Juan de Alcala (in: "Quando [nuestro] Dios vistió") y ocupa las pp. 402-404 del códice. En breve saldrá a luz la edición de este ms., preparada por José J. Labrador, Ralph DiFranco y José M. Rico. 
sus conpetidores tenía conosçida ventaja. Pues como certase [sic] Jorje de Montemayor a allarse allí vn día de la dha. fiesta y le lleuase el premio con sola media copla que hizo, que fue esta:

Aquel que todo lo supo, que es el que todo lo saue, solo Él uasta que os alaue, pues en vro. vientre cupo y en todo el mundo no caue ${ }^{20}$.

Quedó tan corrido y afrentado que luego propuso en su ymaginaçión la venga $[s i c]$, y como viniesse a su noticia que en la pasión que Montemayor auía conpuesto estauan dos coplas a las quales se podían dar divuersos sentidos, mirólas y después de muy consideradas, acordó de escreuir al Montemayor vna carta. Pero para que la carta y la respuesta del Montemayor y la réplica que sobre ella el calçetero enbió sentienda mejor, será bien poner aquí las dos coplas quel Montemayor puso en la pasión que hizo, de donde Alcalá tomó ocasión de escreuirle, las quales son estas:

Siendo ya el tiempo llegado...21

Como se ve, la nota es tan pormenorizada en varios aspectos que difícilmente se podría calificar de inventada o pergeñada por un copista. Según esto, el contrincante de Montemayor bien podría ser ese calcetero radicado en Alcalá de Henares y poeta habitual en las justas de la villa ${ }^{22}$. De todos modos, la cuestión no queda resuelta ni mucho

${ }^{20}$ No hemos podido localizar esa quintilla entre los versos conocidos de Montemayor, aunque sí algunos cercanos. Por ejemplo, estos de Las obras en que habla la Misericordia a la Virgen: "Fue tu condición así, / que, preciándote de mí, / en tu vientre el mundo cabe, / y aunque te ven y te vi, / solo el que te hizo sabe / lo mucho que hizo en ti" (Poesía completa, pp. 167-168); cf., asimismo, p. 797. La misma quintilla, rotulada como "Letra", sin nombre de autor y con algunas ligeras variantes, aparece glosada en el cód. 3071 de la Biblioteca Nacional de Lisboa, ff. 125v-127. La glosa, que empieza: "La immensa y summa deidad" no nos parece de Montemayor, dicho con todas las reservas.

21 Transcribimos, regularizando el uso de las mayúsculas y modernizando acentuación y puntuación, a partir del ms. II-1580 de la Biblioteca Real, ff. 229-229v; cf. A. Getino, op. cit., pp. 332-335. La nota introductoria termina con los versos de Montemayor que hemos puesto más arriba, pero copiados aquí con algunas variantes: 2 quando; 4 caiga; 5 vmanal; 6 estando; 7 juntos; 10 mal delgado de la fe; $11 \mathrm{om}$. Y; 16 El vno sin vida vmana; 18 cristiana; 19 Vno estaua allí en la mesa. La transcripción del padre Alonso Getino, aparte de introducir leves retoques, copia un total de veinticinco versos encabezados por "Aquel que todo lo supo". En realidad se trata de diferentes variaciones sobre la media copla que hemos trasladado, copiadas en el códice al lado y debajo de aquélla.

${ }^{22}$ En nuestra búsqueda de otros posibles poemas de Juan de Alcalá hemos topado con dos atribuidos a "Alcalá" en el ms. II-617 de la Biblioteca Real, ff. 217v-219v; véase Cancionero de poesías varias. Manuscrito no. 617 de la Biblioteca Real de Madrid, eds. J. J. Labrador, C. A. Zorita y R. A. DiFranco, El Crotalón, Madrid, 1986, pp. 339-342. 
menos. Cabe preguntarse, por lo menos, si estamos ante dos autores homónimos, uno sevillano y otro alcalaíno, o si en realidad los dos son el mismo. Si éste fuera el caso, nos inclinamos a pensar que se trata de un poeta complutense que participó ocasionalmente en justas poéticas sevillanas ${ }^{23}$.

\section{CON VISTAS A UNA NUEVA EDICIÓN: \\ COLACIÓN EXTERNA DE LOS TESTIMONIOS}

Pese a la existencia de las ediciones ya reseñadas, la disputa entre $\mathrm{Al}$ calá y Montemayor no cuenta todavía con un texto establecido críticamente ${ }^{24}$. La razón estriba sin duda en la abundancia de copias, dispersas en cartapacios de poesías varias por bibliotecas de medio mundo. José J. Labrador y Ralph DiFranco, incansables en la enorme tarea de repertoriar la lírica áurea, han registrado hace poco hasta once testimonios diferentes, y el número no para de crecer $^{25}$. La posibilidad de acometer, pues, una nueva -no caigamos en la tentación de decir definitiva- edición de esos textos está abierta, y es nuestro propósito darla en un futuro no lejano. Mientras tanto, aprovecharemos estas páginas para ir sentando las bases de ese futuro trabajo.

Los testimonios que hasta ahora hemos podido localizar y cotejar de la controversia son doce, que enumeramos e identificamos con sus correspondientes siglas ${ }^{26}$ :

El segundo de ellos (Coplas de Alcalá a la muerte de la condessa de Oropesa, in: "Vengo a uer la sepoltura") parece anterior (cf. BRIAN DutTon, El Cancionero del siglo XV, c. 13601520, Biblioteca Hispánica del Siglo XV, Salamanca, t. 2, ID2090). En cuanto al primero (A la Trinidad, in: "O muy Sancta Trinidad"), no vemos impedimento para que pueda ser de nuestro Juan de Alcalá.

${ }^{23}$ J. CARo BAROJA (op. cit., t. 1, p. 435) menciona un sastre alcalaíno de nombre Diego de Alcalá, judío bautizado cuando la conversión general promovida por los Reyes Católicos. ¿Podría ser un ancestro de Juan de Alcalá?

${ }^{24}$ El deficiente estado editorial de la controversia no pasó inadvertido a José Manuel Blecua, quien tratando del ms. II-1580 de la Biblioteca Real menciona "...la conocida diatriba de Juan de Alcalá con Jorge de Montemayor, tan copiada como mal editada" ("Epígrafes curiosos en sonetos del siglo xvı", Hommage à Robert Jammes, Presses Universitaires du Mirail, Toulouse, 1994, t. 1, p. 75).

${ }^{25}$ Véase Cancionero sevillano de Lisboa, pp. 293-294. Agradecemos vivamente a JoSÉ J. LABRAdor y RalPH DiFranco el habernos comunicado a lo largo de varios años los datos que iban recopilando sobre la disputa en la BIPA ("Bibliografía de la Poesía Áurea"), que preparan con los auspicios de la National Endowment for the Humanities y de las universidades de Denver y Cleveland. Un anticipo ofrecieron los autores en su Tabla de los principios de la poesía española. Siglos XVI-XVII, pról. A. L-F. Askins, Cleveland State University, Cleveland, 1993.

${ }^{26}$ Además de estas doce, tenemos noticia de otras dos copias que hasta ahora no hemos podido cotejar. Una es la que vio Marcelino Menéndez Pelayo en la Biblioteca de la Universidad de Leiden (Holanda), cuyo encabezamiento anota así: "Jorje de Montemayor, criado de la princesa, hizo un cancionero en el qual hizo la passion 
A Real Academia Española (Madrid), ms. RM6925, ff. 73v-76r: Satira de Juan de Alcala sastre a Jorge de Monte Mayor el de la Diana porque en vn cancionero a lo diuino dijo no se que disparates por lo qual lo vedaron. Sigue: Respuesta de Monte Mayor. Respuesta de Juan de Alcala. Texto a doble columna. Cartapacio de poesías varias. Fecha: 1601. Ex Rodríguez-Moñino y Brey Mariño27.

$H$ The Hispanic Society of America (New York), B 2341, ff. 94v-103v: Contrabersia [sic] entre Joan de Alcala vezino de Sevilla y Xorje de Montemayor. Sigue: Joan de Alcala. Monte Mayor a Joan de Alcala. Torna a responder Joan de Alcala. Códice misceláneo. Fecha: 1600-1650. ExJerez de los Caballeros ${ }^{28}$.

L Biblioteca Nacional (Lisboa), F.G. Cod. 3072, ff. 19v-22v: Coplas de Alcala sastre a Jorge de Montemayor reprehendiendole vna copla. Sigue: Respuesta de Montemayor. Replica de Alcala. Texto a doble columna. Título del códice: Poesias varias de diversos authores em castelhano. Fecha: 1580-159029.

N1 Biblioteca Nacional (Madrid), ms. 12.622, ff. 172v-175v: Epistola inbiada por Juan de Alcala vezino de Seuilla, a Jorge de Montemayor portugues contradiziendole vn pie de vnas coplas que hizo en la Pasion de nro. Sr. Jesuxpo. Sigue: Respuesta de Montemayor. Respuesta de Juan de Alcala. Y a las mismas coplas seis de Montemayor que a replicado torna [palabra ilegible] el Juan de Alcala a replicar y en los mismos consonantes dellas. Texto a doble columna. Cartapacio de poesías varias. Fecha: $1600^{30}$.

N2 Biblioteca Nacional (Madrid), ms. 17681, ff. 250-252r: Coplas de Joam de Alcala ropero de Sevilla contra Monte Mayor hacerca de vn paso que dixo tratando de Xpo. Sigue: Respuesta del Montemayor al Ioan de Alcala. Texto a doble columna. Título del códice: Versos, prosas y apotegmas de Garcia Ruiz de Castro. Fecha: ca. 1580. Ex Gayangos ${ }^{31}$.

glosada, dirigida al Principe de Portugal, y en el primer pie de copla dijo un descuido en el qual hizo a Christo Trinidad, y viendo la dicha obra un Juan de Alcalá, calcetero, vezino de la ciudad de Sevilla, muy gentil poeta, acotó aquel descuido, y envió una reprehension al dicho Jorje de Montemayor, que dize ansi" (Origenes de la novela, CSIC, Madrid, 1943, t. 2, p. 256). De la otra copia da noticia Donatella Pini, "El cancionero bilingüe de Padua (ms. 1526, Biblioteca Universitaria)", en Canzonieri iberici, eds. P. Botta, C. Parrilla, e I. Pérez Pascual, Università di Padova-Universidade da Coruña, Toxosoutos-Noia (La Coruña), 2001, t. 2, pp. 331-334; los textos de la polémica figuran en los ff. $55 \mathrm{v}-67 \mathrm{v}$.

27 Esta fecha, como la mayoría de las que se irán dando para los distintos códices, procede de las que Labrador y DiFranco recogen en la BIPA y van ofreciendo en las notas de sus diversas ediciones.

28 Antonio Rodríguez-Moñino y María Brey Mariño, Catálogo de los manuscritos poéticos castellanos existentes en la Biblioteca de The Hispanic Society of America (siglos XV, XVI, XVII), The Hispanic Society of America, New York, 1965, t. 1, LV, núms. 12, 13, 14.

${ }^{29}$ Ed. cit. de J. J. Labrador Herraiz, R. DiFranco y A. López Budia, pp. 71-80.

${ }^{30}$ Aparte de los rótulos reseñados, el poema presenta otros varios alusivos al juego de réplicas y contrarréplicas por parte de los contendientes.

${ }^{31}$ Es el texto editado por J. LóPez Toro, art. cit., pp. 20-28. Describe el códice Pedro Roca, Catálogo de los manuscritos que pertenecieron a D. Pascual de Gayangos existentes en la Biblioteca Nacional, Tip. de la RABM, Madrid, núm. 726, 26. 
$P \quad$ Palacio de Peralada (Peralada, Gerona), ms. 091 (R. 49.481), ff.185v186v: Epistola que Juan de Alcala escriuio a Iorge de Montemayor portugues, y su respuesta, sobre que emendase vn pie de vna copla y lo demas, etc. Sigue: Respuesta de Iorge de Montemayor. Replica de Juan de Alcala. Texto a triple columna. Códice con prosas y poesías varias. Fecha: 1595-161032.

R1 Biblioteca Real (Madrid), ms. II/570, ff. 144-147: Carta de Juan de Alcala a Jorje de Montemayor y rrespuesta y rreplica, de entranbos. Sigue: Alcala. Respuesta de Montemayor. Replica de Alcala. Responde Alcala a cada copla de Montemayor por los consonantes. Texto a doble columna. Título del códice: Varias poesías. Fecha: 1580-1600. Ex Gondomar ${ }^{33}$.

R2 Biblioteca Real (Madrid), ms. II/973, ff. 194-197v: Siguese vna question entre Alcala y Montemayor. Precede al texto este encabezamiento: Belhezes de varios autores. Sigue: Respuesta. Respuesta. Tres coplas en que enmienda Juan de Alcala a Montemayor. Texto a doble columna. Cartapacio de poesías varias. Fecha: 1586. Ex Gondomar ${ }^{34}$.

R3 Biblioteca Real (Madrid), ms. II/1578 (5), ff. 304-306v: Carta de vn calçetero de Seuilla llamado Alcala en reprehension de vna copla de Montemayor en la qual decía Vno y trino y respuesta de Montemayor y otra suya. Sigue: Respuesta de Montemayor. Respuesta de Alcala a George de Montemayor. Respuesta de Alcala aora a las otras cossas que Montemayor toco en la suya. Texto a doble columna. Cartapacio de poesías varias. Fecha: XVI-XVII ${ }^{35}$.

R4 Biblioteca Real (Madrid), ms. II/1580 (2), ff. 229-232v: Carta de Juan de Alcala calcetero, a Jorje de Montemayor: y otra replica de Juan de Alcala. Sigue: En la villa de Alcala... (nota introductoria reproducida más arriba). Carta de Alcala a Monte Mayor. Respuesta de Monte Mayor a Alcala. Replica de Alcala a Monte Mayor. Texto a doble columna. Título del códice: Cartapacio de Ramiros, Cid y Piscina. Fecha: $1590^{36}$.

32 Hay descripción de Pierre Alzieu, "Las poesías del manuscrito 091 de la biblioteca del Castillo de Peralada", Hommage à Robert Jammes, t. 1, pp. 1-18; referencias: núms. 31, 32 y 33.

${ }^{33}$ Véase M. Luisa López Vidriero (dir.), Catálogo de la Real Biblioteca, t. 11: Manuscritos, Patrimonio Nacional, Madrid, 1994, vol. 1, p. 230, núm. 56. Previamente (ms., f. 117, col. $a$; ibid., p. 229, núm. 26) están copiadas tres coplas y media del primer ataque de Alcalá, pero tachadas luego con un trazo sobre cada una de ellas. Tienen algunas variantes con respecto a la ya reseñada y llevan este encabezamiento: Carta de Juan de Alcala a Montemayor. Sobre vn hierro que puso en la segunda copla de la Pasion que conpuso.

${ }^{34}$ Véase M. L. López Vidriero, op. cit., vol. 1, p. 491, núm. 123; y José J. Labrador HerRaiz, Ralph A. DiFranco y Lori A. Bernard, "El manuscrito Fuentelsol (MP II-973) con poemas de fray Luis de León, fray Melchor de la Serna, Hurtado de Mendoza, Liñán, Góngora, Lope y otros", AnMal, 20 (1997), 189-265; referencias: núms. 230, 346, 229.

35 Véase M. L. López Vidriero, op. cit., vol. 2, p. 112, núm. 7; y Ralph A. DiFranco y José J. Labrador Herraiz, "MS. 1578 de la Biblioteca Real de Madrid con poesías de Cetina, Figueroa, Hurtado de Mendoza, Montemayor y otros", BBMP, 69 (1993), 271-305; referencias: núms. 150-153.

36 Véase M. L. López Vidriero, op. cit., vol. 2, p. 143, núm. 284 (cf. RAMÓn MENÉNDEZ PIDAL, "Cartapacios literarios salmantinos del siglo XvI", BRAE, 1, 1914, 307-314). Texto editado por el padre Alonso Getino, op. cit., pp. 332-342. 
$V$ Biblioteca Apostolica Vaticana (Ciudad del Vaticano, Roma), Cod. Reg. Lat. 1635, ff. 56-58v: Carta de Juan de Alcala a Jorge de Montemayor sobre el herror que hizo en vnas coplas de la Pasion en su cancionero que son estas. Sigue: Contradize Juan de Alcala por carta. Respuesta de Montemayor a Alcala. Contrarespuesta de Juan de Alcala a Jorge de Montemayor. Texto a doble columna. Cartapacio de poesías varias. Fecha: 1570-1580. Ex Cristina de Suecia ${ }^{37}$.

Z Biblioteca Nacional (Madrid), ms. 2790, ff. 249-2 53: De vna agradable conpetencia de dos trobadores despaña. Sigue: Como todo mi yntento en este trabajo... (Presentación en prosa). Alcala a Monte Mayor primero lo que se sigue loandole. Respuesta de Monte Mayor a Alcala. Replica Alcala. Texto a doble columna. Título del códice: Luis Zapata, Miscelánea.. Fecha: ca. 159038.

La abundancia de copias conservadas hace suponer una amplia difusión manuscrita, que ha podido propiciar cruces y contaminaciones. Los textos proceden en su práctica totalidad (salvo el último) de cartapacios formados de acarreo por aficionados. La relativa distancia cronológica de las copias con respecto al momento de la polémica (no menos de 25 años en el mejor de los casos) implica que seguramente los copistas han debido trabajar con materiales deteriorados por el tiempo y el uso. A poco que se analizan los testimonios, resulta evidente que varios de ellos proceden de modelos faltos de alguna hoja o que las tenían desordenadas. Las deturpaciones llegan a tal grado que en la mayoría de los códices la diatriba aparece incompleta y, en algunos casos, gravemente desfigurada en cuanto a su desarrollo lógico y argumental. Por ello, la primera tarea del editor ha de ser realizar la colación externa de los códices con idea de poner orden en ellos ${ }^{39}$, antes de pasar al cotejo de las variantes menudas de los textos, que las hay y muchas.

Dentro de esa colación externa, hay que empezar señalando la diferente agrupación estrófica que presentan los versos según los diversos manuscritos: sólo tres testimonios $(L, P$ y $V$ ) presentan la correcta disposición en coplas reales, mientras que el resto lo hace en quintillas ${ }^{40}$. Seguidamente, conviene proponerse algo tan elemental como cuántas piezas componen la polémica y cuántos versos tiene

37 Describe el códice Harold G. Jones, "El cancionero español (Cod. Reg. Lat. 1635) de la Biblioteca Vaticana”, NRFH, 21 (1972), 370-392; referencias: núms. 124, 125,203 y 209.

38 Es el ya citado Memorial de Luis Zapata. Texto cotejado por J. López Toro en su art. cit.

39 Sobre el concepto de colación externa, véase Germán Orduna, Ecdótica. Problemática de la edición de textos, Reichenberger, Kassel, 2000, pp. 186 ss.; y José MANUEL Lucía Megías, "Manuales de crítica textual: las líneas maestras de la ecdótica española”, Revista de Poética Medieval, 1998, núm. 2, 129-132.

${ }^{40} \mathrm{~N} 2$, por su parte, copia en coplas reales la primera pieza de la diatriba, y luego continúa en quintillas. 
cada una de ellas. La respuesta es que la disputa se compone, no de tres (como aparece en los testimonios hasta ahora editados), sino de cuatro poemas, lo que hace un total de 44 coplas reales, esto es, 440 versos. La secuencia de tales componentes es como sigue: 1) carta de Juan de Alcalá: "Monte fértil lusitano", 60 versos en seis coplas (esquema: ababa:cddcd); 2) respuesta de Montemayor: "So palabras de loor”, 60 versos en seis coplas (esquema: abbab:cddcd); 3) réplica de Juan de Alcalá: "Montaña seca y nublosa”, 200 versos en veinte coplas (esquema: abaab:ccddc); 4) otra réplica de Juan de Alcalá: "Tu sopa fue sin sabor", 120 versos en doce coplas (esquema: abbab:cddcd las seis primeras, que repiten los consonantes de la réplica de Montemayor; abbab:cdcdc las que hacen los números 7, 8, 11 y 12; abaab:cdcdc la 9 y la 10, que son las dos coplas primeras de la Pasión de Montemayor). Este es el poema que ha permanecido oculto hasta ahora para los editores y estudiosos de la polémica.

Los únicos manuscritos que copian íntegramente la diatriba son: $H, N 1, P$ y $R 1$. Pero en el primero de los cuatro el orden de las estrofas ha sufrido un formidable trajín; y en el tercero se han descabalado un par de coplas, además de faltar la separación entre ese poema y el cuarto. En otros códices, algunas quintillas sueltas o formando copla de la cuarta pieza aparecen intercaladas o añadidas en la tercera; así ocurre en $R 2$ (siete quintillas), $R 4$ (ocho), $V$ (cuatro) y $Z$ (doce $)^{41}$. Aquellos cuatro testimonios integran, pues, un grupo diferenciado del resto, que se limitan a copiar sólo las tres primeras composiciones, con las matizaciones ya indicadas para $R 2, R 4, V y Z$. Dentro de este segundo grupo hay un solo códice que copia las 32 coplas correspondientes a las tres primeras piezas. Se trata de $R 4$, que presenta, sin embargo, dos deficiencias en el tercer poema: la transmutación en el orden de dos quintillas y la ya señalada intercalación de ocho correspondientes al cuarto.

En cuanto a los demás testimonios, la situación es la siguiente: $A$ ha perdido tres quintillas en el tercer poema; a $L$ le faltan una del segundo y dos del tercero; en $N 2$ hay una laguna de cinco quintillas consecutivas en el segundo; $R 2$ está falto de siete quintillas en el tercero; ahí mismo $R 3$ dejó de copiar diez quintillas salteadas, y $V$ nada menos que 20; a $Z$, en fin, le faltan cuatro del mismo poema. Además, $R 2$ y $V$ presentan notables transmutaciones en el orden de las estro-

${ }^{41}$ A las ocho quintillas consignadas para $R 4$ habría añadir las dos estrofas completas de Montemayor que forman parte de la cuarta pieza, copiadas al final de la nota introductoria que va transcrita supra. También están copiadas esas dos estrofas encabezando el texto de $V$. Particular interés reviste el que la intercalación de $R 4$ y la de $Z$ se produzca exactamente a la misma altura del tercer poema (v. 80); que es también donde $R 3$ introduce indebidamente este rótulo: Respuesta de Alcala a las otras cossas que Montemayor toco en la suya. 
fas. La distinción de estos dos grupos de testimonios no implica necesariamente, sin embargo, que no existan relaciones de filiación entre códices de un grupo y otro, ya que las omisiones han podido producirse a partir de un modelo textualmente íntegro. Esto sólo se podrá determinar con el análisis de las variantes en los diferentes loci critici del texto. A la vista de estos datos, la transmisión y estado editorial de los cuatro poemas que componen la controversia ofrece, al día de hoy, el siguiente balance: 1) los poemas primero y segundo son los mejor transmitidos por el conjunto de los testimonios. Por eso mismo, son los mejor editados hasta ahora; 2) el poema tercero nos ha llegado íntegramente en media docena de los testimonios aquí reseñados. De ellos, se han editado dos: $R 4$ por el padre Alonso Getino y, con texto menos deturpado, N2 por López Toro; 3) el poema cuarto nunca ha sido editado como tal hasta ahora, a pesar de que cuenta con cuatro testimonios íntegros, más cuatro fragmentarios.

La integración de este cuarto poema en el decurso textual de la polémica propone la duda de si pudo existir una segunda y desconocida réplica de Montemayor. A esa posibilidad alude precisamente Alcalá en la última estrofa de "Montaña seca y nublosa", que dice así:

Pues bien es que concluyamos

con estas que son terceras;

pues de Trinidad hablamos,

que con tres solas partamos

en paz y gracia las peras.

Porque si tú me replicas

y replicando me picas,

téngote de replicar,

y replicando picar,

y aun repicar si repicas.

Es verdad que el sentido de la estrofa resulta equívoco, por mor del v. 192. Este podría referirse, bien al propio poema del que forma parte, bien al siguiente ("Tu sopa fue sin sabor"). En el primer caso, el verso significa que ya van tres poemas cruzados (uno de Montemayor y dos de Alcalá), con lo que el otro de Alcalá sería algo así como una propina añadida con posterioridad. En el segundo caso, el verso 192 cumple la función de anunciar el poema que viene detrás ("Tu sopa fue sin sabor"), al tiempo que la copla entera reta a Montemayor a replicar de nuevo, si se atreve. De manera que esas terceras coplas lo serían sólo en el cómputo de la participación de Alcalá en la disputa. Esto nos parece más verosímil, dado que "Tu sopa fue sin sabor" no es, en absoluto, un añadido más o menos circunstancial a la discusión, sino su remate imprescindible. Así se ve en el plano métrico, por el hecho de repetir en sus seis primeras estrofas, como ya se dijo, los consonantes de "So palabras de loor". Y en el plano lógico-argu- 
mental, porque contiene una propuesta de enmienda para el error teológico que dio pie a la polémica (véase el texto en el Apéndice).

No hay el menor indicio de que Montemayor replicase por segunda vez a Alcalá. Todo indica, pues, que hubo de limitarse a callar y esperar la publicación del Segundo cancionero espiritual para corregir su inadvertencia (aunque no, desde luego, con la enmienda que le había brindado su rival). En el prólogo de ese libro, el poeta, como si quisiera curarse en salud, dice haberlo enseñado antes de publicarlo a muchos teólogos, y menciona especialmente a los dominicos del colegio de San Gregorio en Valladolid. Pero esta cautela se volvió en su contra, ya que dicho colegio era feudo de los dominicos carrancistas y fray Bartolomé Carranza, arzobispo de Toledo, fue precisamente la víctima más ilustre de la ola represiva desatada en 1558 contra los sospechosos de luteranismo. Así que la poesía devota de Montemayor salió de la sartén de Alcalá para caer en el fuego de la Inquisición. Cabe pensar que los muy difundidos versos satíricos del oficial de la aguja contribuyeron en algo a ese desenlace. En cualquier caso, no era indispensable: el simple hecho de ser un laico - "honrado y discretísimo romancista" 42 - metido a escribir en materias de espiritualidad ya había puesto a Montemayor en el punto de mira de los censores.

La historia literaria tenía reservada todavía un último avatar en el Siglo de Oro para la Pasión de Montemayor. Y es que la muerte civil decretada por el Índice inquisitorial no se cumplió del todo. Por algún camino extraño, el poema reapareció años más tarde, sin el nombre de su autor, en una interesante antología de poesía moral y religiosa: la Primera parte del thesoro de divina poesía recopilada por Esteban de Villalobos ${ }^{43}$. Villalobos o quien fuese que preparó el texto debía conocer las coplas de Alcalá, pues cuando llegamos al verso 11 nos topamos con su corrección: "Y estando alli el rey begnino [sic]". Pero ahí no termina la cosa: tras un triple salto mortal, el poema condenado en el siglo XVI acabó teniendo acogida, ya en el siglo Xx, en una Biblioteca de autores dominicos... ${ }^{44}$. Los caminos del Señor son, en verdad, inescrutables.

JUAn Montero

Universidad de Sevilla

42 F. Márquez Villanueva, art. cit., p. 278.

43 Juan Rodríguez, Toledo, 1587. El libro tuvo dos ediciones más: Iorge Rodriguez, Lisboa, 1598; y Luys Sánchez, Madrid, 1603 (cf. Antonio RodríGuez-MoÑIno, Manual bibliográfico de cancioneros y romanceros, Castalia, Madrid, 1973-1978, t. 1, pp. 691-701). En la primera edición el poema ocupa las pp. 54-125; va precedido de esta portadilla: "La Sagrada Passion de nuestro Redemptor Iesu Christo en redondillas. Sacada a luz por Fray Pedro Iuan Micon”. Sobre este Micón, véase la nota siguiente.

${ }^{44}$ Fray Pedro Juan Micón, La Sagrada Pasión de Nuestro Redentor Jesucristo, introd. P. Luis G. Alonso Getino, Tip. de "El Santísimo Rosario”, Vergara, 1925; en la porta- 


\section{APÉNDICE}

Por su interés para el conocimiento de la controversia y por estar inédito hasta ahora, transcribimos a continuación el poema "Tu sopa fue sin sabor", según el texto del testimonio R1. Lo hacemos desarrollando las abreviaturas, regularizando el uso de las mayúsculas y modernizando la puntuación y la acentuación.

Responde Alcalá a cada copla de Montemayor por los consonantes

Tu sopa fue sin sauor, más que la dio cortesano, nj que el más simple aldeano naçido en Monte Mayor, ques pueblo bajo y villano.

Tus metros son la granuja que, estando en la sedería, tu abuelo se los comja con la punta de el aguja quando botones haçía.

Heziste que se pregone

la falta de tu sauor, [sic] porque aquí no puede ser concomitante rratione, ni lo saues disçerner.

$\mathrm{Ni}$ es rrespuesta verdadera, ni conpetente nj clara, mas çierto más azertara si al manjar se ref[i] riera que se guisa sobre el hara.

Tú pones escuridad en lo claro, y es ansí que quien tú diçes aquí no le doy yo claridad, mas della la rresçibí.

da aparece el marbete: "Biblioteca Clásica Dominicana". Agradecemos a Elizabeth Rhodes que nos haya dado a conocer esta curiosa edición del poema. El padre GETINo no pudo comprobar en 1925 que se trataba de la Pasión de Montemayor por no tener a mano ninguno de los raros ejemplares que conservan su poesía devota. Así se expresaba en 1929, tras editar la polémica por el texto de R4: "Además de la curiosidad de esta polémica del calcetero de Alcalá con el autor de la Diana..., el manuscrito nos ofrece la curiosidad de un nuevo problema de crítica literaria: las dos estrofas que aquí se copian, atribuidas a Montemayor y que él en su respuesta no rechaza sino que parece aceptar enteramente, son las primeras del Canto primero del poemita a la Pasión del valenciano P. Micó, Maestro de S. Luis Beltrán y antiguo estudiante de Salamanca. ¿Tomó él esas dos estrofas del famoso poeta portugués o las tomó él del lusitano? Más bien parece lo primero, ya porque Montemayor no niega la paternidad de ellas, ya porque en Micó aparecen con la corrección propuesta por el calcetero" (op. cit., pp. 342-343). 
Y con la luz que medio, avnque pecador yndigno, entendí tu desatino y el rigor con que salió de tu sentido malino.

En tu pedernal se esmalta el fuego y de ti depende, y sin yesca y leña enprende una zentella que salta y por el monte se estiende.

Y si tal fuego no ataja

la humjledad [sic] de tu escuela, tu soberbia se rreuela; y el mayor fuego abentaja quando menos se rrebela.

Siendo tú tan buen marrano, me quisiste motejar: mejor te fuera callar, que a ti tarde nj tenprano te quisieron cristianar.

Quando niño se te dio la vieja çircunçisión, porque eres de aquel montón que de Castilla salió por crimen de la Pasión.

Pues bien es que te rrepese el pesar con que te ofendes, y si en el peso desçiendes, que la fee te contrapese y de tal pesar te emjendes.

Mas avnque más te blasone, no te das por ello vn higo, porque no ay en ti castigo ni tu rrazón se conpone a que te acuerdes comjgo.

Mas tanbién es menester, amjgo Monte Mayor, que ynformemos al letor si pudieras componer tu copla sin este herror.

Y que fuera tan bastante su sentido y eloquençia, y no menos elegante, si no la misma sentençia, con mudar vn consonante. 
Pues para haçer yo así

y dar clara rrelaçión de lo que rreprehendí, de esta trobada Pasión porné dos coplas aquí.

Siendo ya el tiempo llegado en que Cristo determina de ponerse en tal estado que caiga sangre diuina sobre el humano pecado; se puso el Señor en pie, con sus discípulos junto, a la mesa donde fue echo y hordenado el punto más delicado de fee.

$Y$ estando alli el Vno y Trino con su compaña rreal, luego en el ynstante vino el cordero material ante el Cordero diuino.

Vno sin vida, a la llana, y el otro sobre quien pesa la rreparaçión humana; vno está de noche en mesa, y otro en cruz por la mañana.

Pues para que tú no herraras fuera menester buscar, porque el trobar es hallar, y si buscaras, hallaras y trobaras sjn herrar.

$\mathrm{Y}$ así dixeras diuino adonde Trino pusiste; y siguiendo el mjsmo tino, donde diuino dixiste, pudieras poner benigno.

Y esto, no para enseñarte (porque dártelo a sentir será nunca concluir), pero para disculparte pudieras así deçir:

Estando allí el rrey benigno con su compaña rreal, luego en el jnstante vino el cordero material ante el Cordero diuino. 